\title{
A Full Automatic Device for Sampling Small Solution Volumes in Photometric Titration Procedure Based on Multicommuted Flow System
}

\author{
Sivanildo S. Borges, ${ }^{1,2}$ Gláucia P. Vieira, ${ }^{1}$ and Boaventura F. Reis ${ }^{1}$ \\ ${ }^{1}$ Centro de Energia Nuclear na Agricultura, Universidade de São Paulo, Avenida Centenário 303, 13400-970 Piracicaba, SP, Brazil \\ ${ }^{2}$ Centro de Ciências Exatas e Tecnológicas, Universidade Federal do Recôncavo da Bahia, 44380-000 Cruz das Almas, BA, Brazil
}

Received 9 April 2007; Accepted 7 June 2007

In this work, an automatic device to deliver titrant solution into a titration chamber with the ability to determine the dispensed volume of solution, with good precision independent of both elapsed time and flow rate, is proposed. A glass tube maintained at the vertical position was employed as a container for the titrant solution. Electronic devices were coupled to the glass tube in order to control its filling with titrant solution, as well as the stepwise solution delivering into the titration chamber. The detection of the titration end point was performed employing a photometer designed using a green LED $(\lambda=545 \mathrm{~nm})$ and a phototransistor. The titration flow system comprised three-way solenoid valves, which were assembled to allow that the steps comprising the solution container loading and the titration run were carried out automatically. The device for the solution volume determination was designed employing an infrared $\operatorname{LED}(\lambda=930 \mathrm{~nm})$ and a photodiode. When solution volume delivered from proposed device was within the range of 5 to $105 \mu \mathrm{l}$, a linear relationship $(\mathrm{R}=0.999)$ between the delivered volumes and the generated potential difference was achieved. The usefulness of the proposed device was proved performing photometric titration of hydrochloric acid solution with a standardized sodium hydroxide solution and using phenolphthalein as an external indicator. The achieved results presented relative standard deviation of $1.5 \%$.

Copyright (C) 2007 Sivanildo S. Borges et al. This is an open access article distributed under the Creative Commons Attribution License, which permits unrestricted use, distribution, and reproduction in any medium, provided the original work is properly cited.

\section{INTRODUCTION}

Generally, in automatic titration procedure based on flow injection analysis process, the volume of the titrant solution delivered has been determined considering both flow rate and time interval elapsed while the titration was run [1-3]. In principle, it has been admitted that the flow rate was constant and the time interval was a very well-controllable variable $[4,5]$. In these cases, peristaltic pump has been the device widely used to propel titrant solution [6-8]. Because pumping pulsation, due to peristaltic pump, could impair the precision of the delivered solution volume, a synchronization strategy has been implemented $[4,9]$. Since peristaltic pump maintain a constant pulsation pattern, small volume of titrant solution, presenting good precision, could be delivered. Nevertheless, to accomplish this requirement, it is necessary to resort facilities comprising electronic and software $[4,9,10]$. Furthermore, the aging of the pumping tube could affect flow rate, thus this effect could become an error source.

In this work, we intend to develop a device with ability to deliver small aliquots of titrant solution, determining also its volume with good precision and accuracy independent of both time and flow rate. The usefulness of the device will be demonstrated, coupling then to an automatic titration module based on multicommutation process $[11,12]$.

\section{EXPERIMENTAL}

\subsection{Solutions}

Purified water with electric conductivity less than $0.1 \mu \mathrm{S}$ $\mathrm{cm}^{-1}$ was used throughout. An $89.2 \pm 0.9 \mathrm{molL}^{-1} \mathrm{HCl}$ solution was prepared by dilution from a $1 \mathrm{molL}^{-1} \mathrm{HCl}$ solution. This solution was standardized by titration using an $88.7 \pm 0.8 \mathrm{molL}^{-1} \mathrm{NaOH}$ solution, which was previously standardized by titration using a potassium biphthalate solution and a $0.01 \%(\mathrm{w} / \mathrm{v})$ phenolphthalein solution as indicator.

\subsection{Apparatus}

The equipment set up comprised a Pentium III microcomputer furnished with an electronic interface card (PCL-711S, Advantech), an IPC-4 Ismatec peristaltic pump with Tygon 


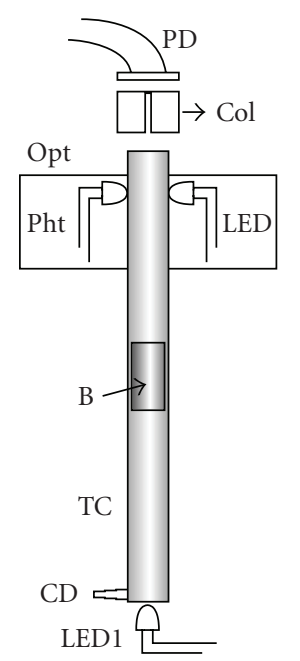

(a)

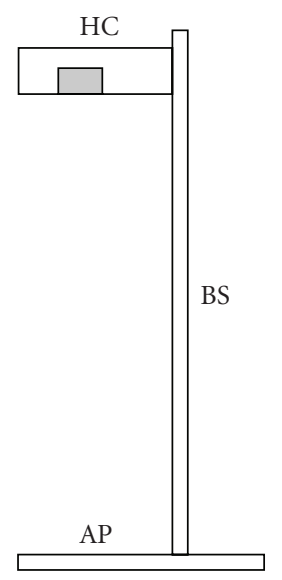

(b)

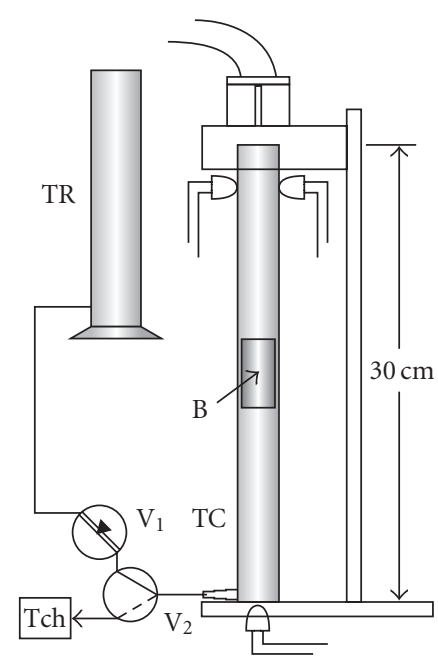

(c)

Figure 1: View of the volume meter. (a) Detailed description of the device: TC = solution container, glass tube $30 \mathrm{~cm}$ long, $0.5 \mathrm{~cm}$ and $0.35 \mathrm{~cm}$ external and inner diameters, respectively; $\mathrm{CD}=$ solution inlet/outlet; $\mathrm{B}=$ floating device, polyethylene vial (transparent) with flat bottom, $25 \mathrm{~mm}$ long, $3.4 \mathrm{~mm}$ external diameter, $0.5 \mathrm{~mm}$ wall thickness; LED and LED1 = infrared light emitting diode $(\lambda=930 \mathrm{~nm})$; Pht $=$ phototransistor (Til78); Col = light beam collimator, metallic piece with dimension of $9 \mathrm{~cm}^{2}$ surface, $3.5 \mathrm{~cm}$ thickness, and central hole (1.0 mm diameter) for light transmission; PD = photodiode (Hamamatsu, S1337-1010BR). (b) Solution container hold; AP = acrylic plate with dimension of $15 \times 20 \times 1.5 \mathrm{~cm}$; BS = brass cylinder, $30 \mathrm{~cm}$ long and $1.0 \mathrm{~cm}$ diameter; $\mathrm{HC}=$ glass tube holder, acrylic plate with dimension $15 \times 10 \times 1 \mathrm{~cm}$. (c) Assembling view of the volume meter: $\mathrm{TR}=$ reservoir of titrant solution; $\mathrm{V}_{1}=$ pinch solenoid valve normally closed; $\mathrm{V}_{2}$ = three-way solenoid valve; $\mathrm{Tch}=$ titration chamber (14). Solid and doted lines into the valve $\left(\mathrm{V}_{2}\right)$ symbol indicate the fluid pathway when valve was switched OFF and $\mathrm{ON}$, respectively.

pumping tubes, six three-way solenoid valves (161T031, Nresearch), one solenoid pinch valve normally closed (161P011, Nresearch), a homemade $12 \mathrm{~V}$ regulated power supply to feed the solenoid valves, a homemade electronic interface [13] to provide the potential difference and current intensity required to drive the solenoid valves, and a homemade photometric detector [14]. The control unit comprised one photodiode (Hamamatsu, S1337-1010BR), one phototransistor (Til78) wired as an optic switch, two infrared LED $(\lambda=930 \mathrm{~nm})$, two operational amplifiers (OP07), one comparator device (LM339), and one transistor (BC547). The assays comprising the volume meter calibration and photometric titration were performed employing a software wrote in Quick BASIC 4.5. Flow lines were of Tygon tubing $0.56 \mathrm{~mm}$ inner diameter.

\subsection{The volume meter description}

In Figure 1, it is shown a front view of the volume meter, where we can see that the device is coupled to the titrant solution reservoir (TR) through the solenoid valves $V_{1}$ and $\mathrm{V}_{2}$. The $\mathrm{V}_{2}$ was assembled to permit the container loading (TC) with titrant solution when valve $\mathrm{V}_{1}$ was switched $\mathrm{ON}$. When the container was filled with titrant solution, the floating device (B) interrupted the infrared radiation beam of the optic switch (Opt). When the electronic interface showed in Figure 2 sensed the interruption of the radiation beam, it generated the control signal to switch OFF valve $V_{2}$ in order to stop the stream of the titrant solution.

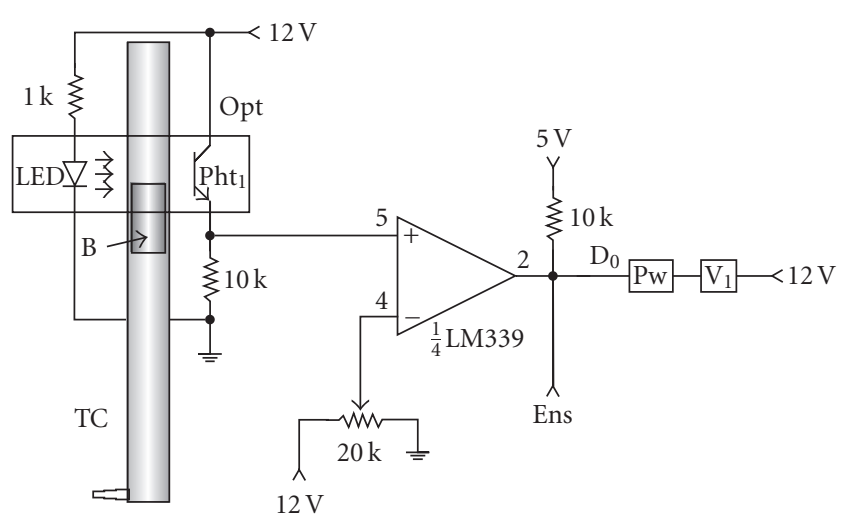

FIGURE 2: Diagram of the device to control the filling of the titrant solution container. Opt $=$ optic switcher, $\mathrm{LED}=$ infrared emitting diode $(930 \mathrm{~nm}), \mathrm{Pht}=$ phototransistor $($ Til78), $\mathrm{Pw}=$ power driving device (ULN2803), $\mathrm{D}_{0}=\mathrm{Pw}$ first input line, $\mathrm{V}_{1}=$ pinch solenoid valve normally closed, Ens = control enabling line.

The optic switch (Opt) comprising an infrared radiation emitting diode $(\lambda=930 \mathrm{~nm})$ and a phototransistor (Til78), which was attached in a metallic piece $(5 \times 5 \times 0.4 \mathrm{~cm})$ with a central lead hole to permit the inserting of the solution container (TC), thus allowing that the container was positioned between the phototransistor (Pht) and the infrared LED. A hole with a diameter of $1.0 \mathrm{~mm}$ was drilled at the orthogonal position to the lead hole in order to permit that the infrared 
TABLE 1: Steps sequence of the titration procedure.

\begin{tabular}{|c|c|c|c|c|c|c|c|c|c|c|}
\hline Step & $\mathrm{V}_{1}$ & $\mathrm{~V}_{2}$ & $\mathrm{~V}_{3}$ & $\mathrm{~V}_{4}$ & $\mathrm{~V}_{5}$ & $\mathrm{~V}_{6}$ & $\mathrm{~V}_{7}$ & $\mathrm{D}_{0} \mathrm{Pw}$ & Time (s) & Description \\
\hline 0 & 0 & 0 & 0 & 0 & 0 & 0 & 0 & 0 & - & Standby \\
\hline 1 & 1 & 0 & 0 & 0 & 0 & 0 & 0 & 1 & - & Fill titrant container \\
\hline 2 & 0 & 0 & 0 & 0 & 0 & 0 & 0 & 0 & - & Standby \\
\hline 3 & 0 & 0 & 0 & 0 & 1 & 1 & 0 & 0 & 20 & Fill flow line S and In* \\
\hline 4 & 0 & 0 & 0 & 0 & 0 & 0 & 1 & 0 & 15 & Empting titration chamber \\
\hline 5 & 0 & 0 & 1 & 1 & 0 & 0 & 0 & 0 & 20 & Washing titration chamber** \\
\hline 6 & 0 & 0 & 0 & 0 & 0 & 0 & 1 & 0 & 20 & Empting titration chamber** \\
\hline 7 & 0 & 0 & 0 & 0 & 1 & 0 & 0 & 0 & sit $* * *$ & Sample inserting time \\
\hline 8 & 0 & 0 & 0 & 0 & 0 & 1 & 0 & 0 & 2 & Indicator insertion \\
\hline 9 & 0 & 0 & 1 & 1 & 0 & 0 & 0 & 0 & 8 & Carrier solution insertion \\
\hline 10 & 0 & 1 & 0 & 0 & 0 & 0 & 0 & 0 & - & Start titration \\
\hline 11 & 0 & 0 & 0 & 0 & 0 & 0 & 0 & 0 & - & End titration \\
\hline
\end{tabular}

beam attained the phototransistor (Pht) after it crosses the titrant solution container (TC).

As it is depicted in Figure 1, an infrared radiation emitting diode (LED1) was installed at the bottom of the titrant solution container (TC), thus the radiation beam emitted by this LED was directed towards the photodiode (PD) through the liquid column maintained inside of the container. The liquid column behaves as a wave guide and it was observed that its length affected the intensity of the infrared radiation beam that reaches the photodiode (PD). The volume meter was developed exploiting this effect.

\subsection{The volume meter calibration}

The filling of titrant solution container (TC) was controlled by mean of the electronic interface showed in Figure 2. Prior to load the container with titration solution, the system was adjusted following the steps summarized in Table 1. Maintaining the titrant solution container empty, the signal generated by the optic switch (Opt) was $3.8 \mathrm{~V}$ that was applied to the no inverting input of the comparator device (LM339, pin 5). Reference signal applied to the comparator input (pin 4) was adjusted to $3.5 \mathrm{~V}$ turning the variable resistor $(20 \mathrm{k} \Omega$ ) wired to it. Under this condition, the output of the comparator device (pin 2) was at a high-state condition and the power-driving device $(\mathrm{Pw})$ was maintained deactivate, while the control enabling line (Ens) was at low level $(0 \mathrm{~V})$. When the software was run, the microcomputer sent a control signal (TTL high level) through PCL711 interface card to enable the control line (Ens, Figure 2). Under this condition, the input line $\left(\mathrm{D}_{0}\right)$ of the power-driving device $(\mathrm{Pw})$ was enabled to switch $\mathrm{ON}$ valve $\mathrm{V}_{1}$, thus the titrant solution flowed from its vessel (TR, Figure 1) by the gravity acceleration action to fill the titrant container (TC) with titrant solution. While the liquid column increased into the container, the floating device (B) was displaced toward the top. When it crossed the light beam of the optic switch (Opt), the signal sent to the comparator input (pin 5) fall lower than $3.0 \mathrm{~V}$. Under this condition, the output signal of the comparator device (pin 2) was drove to the low-state condi- tion $(0 \mathrm{~V})$, thus disabling the line input $\left(\mathrm{D}_{0}\right)$ of the powerdriving device $(\mathrm{Pw})$, which switched OFF valve $\mathrm{V}_{1}$ in order to stop the stream of titrant solution. The light emitting diode (LED1) installed in the container bottom (TC, Figure 1) was switched OFF by turning the variable resistor wired to the base of the transistor ( $\operatorname{Tr} 1$, Figure 3$)$. The signal output (So) of the operational amplifier (OA2) was adjusted to $0 \mathrm{~V}$ by turning the variable resistor $(20 \mathrm{k} \Omega$ ) wired to the no inverting input of this operational amplifier. Afterwards, the emission intensity of the LED1 was raised up to the output signal (So) attained $2000 \mathrm{mV}$. This was done turning the variable resistor coupled to the base of the transistor $(\operatorname{Tr} 1)$.

The flow diagram of the titration system is shown in Figure 4. In this configuration, all valves are switched OFF, thus all solutions propelled by the peristaltic pump (PP) are directed towards their storing vessels. When valve $V_{2}$ was switched ON, the titrant solution flowed through it. Aiming to find the relationship between the solution volumes delivered from the container (TC) and the output signal (So) generated by photodiode (Figure 3 ), a set of assays was carried out. The microcomputer sent, through the output port of the PCL711S interface card, a control signal to switch ON valve $\mathrm{V}_{2}$. While solution flowed from the container (TC), the microcomputer read the variation of the signal (So) through the analog input of the PCL711S interface card. When signal variation attained a preset value (Vs), valve $V_{2}$ was switched OFF in order to stop the solution stream, and the delivered volume of solution was measured. Assays were performed programming potentials difference ranging from 50 up to $800 \mathrm{mV}$. After calibration stage, the valve $V_{2}$ was maintained switched $\mathrm{ON}$ during a time interval of 2 minutes to empty the titrant solution container.

After calibration, a set of titration assays was carried out to demonstrate the usefulness of the proposed volume meter, which was implemented using the flow system showed in Figure 4, which was designed based on multicommutation process [10-12]. Titration chamber (Tch) and photometer detector (not showed) were similar to those employed in previous work [14]. 


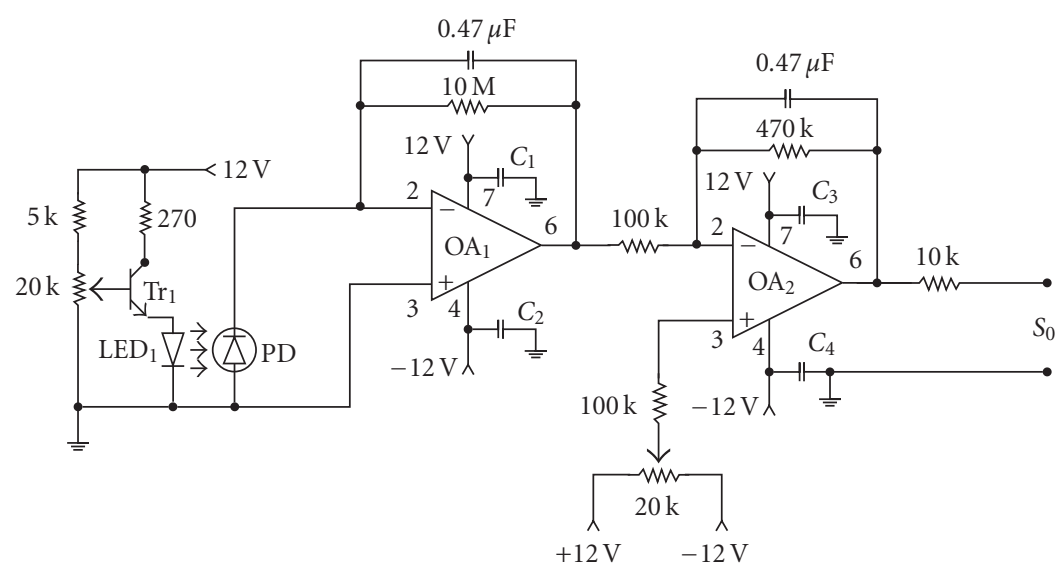

FIGURE 3: Electronic diagram of the interface to monitor the titrant solution into the container. $\operatorname{Tr} 1=\operatorname{transistor}(\mathrm{BC} 547)$, LED1 = light emitting diode $(930 \mathrm{~nm}), \mathrm{PD}=$ photodiode (Hamamatsu, S1337-1010BR), OA1 e OA2 = operational amplifiers (OP07), C1, C2, C3, and C4 = 1 $\mu \mathrm{F}$ tantalum capacitors, $\mathrm{S}_{o}=$ signal output.

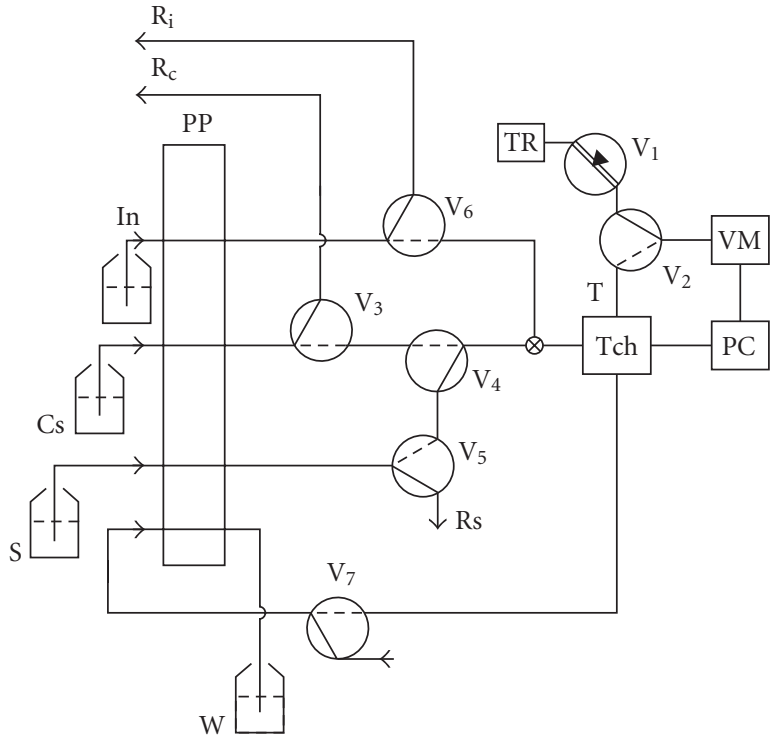

FIgURE 4: Diagram of the flow system. $\mathrm{V}_{1}$, = pinch solenoid valve, $\mathrm{V}_{2}, \mathrm{~V}_{3}, \mathrm{~V}_{4}, \mathrm{~V}_{5}, \mathrm{~V}_{6}$, and $\mathrm{V}_{7}=$ three way solenoid valves, $\mathrm{S}=$ sample; $\mathrm{Cs}=$ carrier solution, water, In $=$ indicator, $0.01 \%(\mathrm{w} / \mathrm{v})$ phenolphthalein solution, Rs, Rc, and $\mathrm{Ri}=$ solutions ( $\mathrm{S}, \mathrm{Cs}, \mathrm{In}$ ) circulation towards their storing vessels, respectively; $\mathrm{W}=$ waste, $\mathrm{PP}=$ peristaltic pump, $\mathrm{T}=$ titrant solution, $88.7 \pm 0.8 \mathrm{molL}^{-1} \mathrm{NaOH}, \mathrm{Tch}=$ titration chamber, $\mathrm{TR}=$ titrant solution reservoir, $\mathrm{VM}=$ volume meter (Figure 1), $\mathrm{PC}=$ microcomputer.

As it is depicted in Table 1, in the standby condition all valves are switched OFF, thus all solutions are pumped back to their storing vessels (Figure 4). When the software was started to carry out a titration run, the microcomputer sent a control signal (TTL high level) through the enabling line (Ens, Figure 2 ) to enable the power-driving device ( $\mathrm{Pw}$, Figure 2). Under this condition, valve $\mathrm{V}_{1}$ was switched $\mathrm{ON}$ to fill the container (TC) with titrant solution. This step was done as it was described in previous section. Afterwards, valves $V_{5}$ and $V_{6}$ were switched ON during a time interval
TABLE 2: Signal generated as function of the delivered water volume.

\begin{tabular}{cc}
\hline Signal $(\mathrm{mV})$ & Volume $(\mu \mathrm{L})$ \\
\hline 56 & 5.7 \\
100 & 10.3 \\
140 & 14.9 \\
165 & 19.0 \\
234 & 28.0 \\
273 & 32.6 \\
318 & 38.4 \\
372 & 46.4 \\
463 & 58.7 \\
559 & 72.5 \\
791 & 103.9 \\
\hline
\end{tabular}

TABLE 3: Comparison between the solution volumes measured and the preset values, results are average of three measurements.

\begin{tabular}{cc}
\hline Measured volume $(\mu \mathrm{L})^{*}$ & Preset volume $(\mu \mathrm{L})$ \\
\hline $17.93 \pm 0.06$ & $17.7 \pm 0.2$ \\
$29.40 \pm 0.05$ & $29.3 \pm 0.3$ \\
$58.6 \pm 0.7$ & $58.8 \pm 0.5$ \\
$76.7 \pm 0.3$ & $77.7 \pm 0.4$ \\
$100.5 \pm 0.6$ & $99.6 \pm 0.7$ \\
\hline
\end{tabular}

* Values obtained weighting the delivered volume of water and considering the water density at $25^{\circ} \mathrm{C}$.

of 20 seconds (step 3) to fill the flow lines up to the titration chamber (Tch). Afterwards, valve $\mathrm{V}_{7}$ was switched $\mathrm{ON}$ during a time interval of 15 seconds (step 4) to empty the titration chamber. The washing of the titration chamber with carrier solution comprised the steps 5 and 6 (Table 1), which were repeated twice to assure good cleaning.

Following the working sequence showed in Table 1 (steps 7,8 ), valves $V_{5}$ and $V_{6}$ were sequentially switched ON during preset time intervals to insert into the titration chamber aliquots of sample solution (S) and of indicator solution (In), 
TABLE 4: Comparison of the titration results, results are average of three consecutive titration run that were performed using a $88.7 \pm$ $0.8 \mathrm{molL}^{-1} \mathrm{NaOH}$ standardized solution.

\begin{tabular}{ccccc}
\hline $\begin{array}{c}\text { Sample } \\
(\mathrm{HCl})\end{array}$ & $\begin{array}{c}\text { Sample volume } \\
(\mu \mathrm{L})\end{array}$ & $\begin{array}{c}\text { Actual HCl concentration } \\
\left(\mathrm{molL}^{-1}\right)\end{array}$ & $\begin{array}{c}\text { Found HCl concentration } \\
\left(\mathrm{molL}^{-1}\right)\end{array}$ & $\begin{array}{c}\text { Difference } \\
(\%)\end{array}$ \\
\hline 1 & 43 & $89.2 \pm 0.9$ & $89.5 \pm 0.6$ & -0.3 \\
2 & 57 & $89.2 \pm 0.9$ & $88.5 \pm 0.9$ & 0.8 \\
3 & 71 & $89.2 \pm 0.9$ & $89.1 \pm 1.5$ & 0.1 \\
4 & 85 & $89.2 \pm 0.9$ & $89.8 \pm 0.5$ & -0.7 \\
5 & 100 & $89.2 \pm 0.9$ & $88 \pm 1$ & 1.3 \\
6 & 115 & $89.2 \pm 0.9$ & $88 \pm 1$ & 1.3 \\
\hline
\end{tabular}

respectively. The time interval to maintain valve $\mathrm{V}_{6}$ switched ON was settled at 2.0 seconds, while time for valve $V_{5}$ was varied from 3.0 up to 8.0 seconds. Afterwards, valves $V_{3}$ and $\mathrm{V}_{4}$ were switched $\mathrm{ON}$ during a time interval of 8.0 to insert $800 \mu \mathrm{l}$ of the carrier solution into the titration chamber.

As it is shown in Table 1 (step 10), valve $V_{2}$ was switched $\mathrm{ON}$ to permit that the titrant solution flowed continuously by the gravity acceleration action toward the titration chamber (Tch). The monitoring of the signal generated by the photometer was performed by the microcomputer through the analog input of the PCL711S interface card. When a quick transition of the generated signal occurred, the microcomputer sent a control signal through the enabling line (Ens, Figure 2) to switch OFF valve $\mathrm{V}_{2}$ in order to stop the stream of the titration solution. This signal changing indicated that the stoichiometric condition was attained [14]. Afterwards, the microcomputer read the signal $\left(\mathrm{S}_{0}\right)$ generated by the photodiode (PD) of the volume meter (Figure 3) that was saved as an ASCII file. The volume of the titrant solution used to find the end of titration was calculated using this measurement. When the signal $\left(\mathrm{S}_{0}\right)$ surpassed a preset threshold value, which was related to a delivered solution volume of the titrant solution about $85 \mu \mathrm{l}$, the microcomputer halted the stream of the titrant solution and saved the signal value related with the solution volume that was used at that moment. Afterwards, the volume meter-filling step was carried out again and after that the titration run was reestablished in order to find the end of titration.

\section{RESULTS AND DISCUSSIONS}

\subsection{General comments}

The volume meter working principle was based on the attenuation of the radiation beam intensity, which was affected by the height of the liquid column inserted between the electromagnetic radiation source (LED1, Figure 1) and the photodiode (PD). The value of the potential difference generated by the photodiode decreased when the gap between the liquid column top and the photodiode (PD) increased. Previous assays performed using LEDs with wavelength of $470 \mathrm{~nm}$ (blue), $650 \mathrm{~nm}$ (red), and $930 \mathrm{~nm}$ (infrared) showed that better linear range could be obtained with the infrared LED. In this sense, the results commented below were obtained employing this component.

\subsection{Volume meter calibration}

Intending to find the relationship between the volume of the solution delivered and the potential difference generated by the photodiode (PD), a set of assays was carried out yielding the results showed in Table 2. Processing these data, we found the following linear relationship: $\Delta \mathrm{E}(\mathrm{mV})=-25.7-$ $7.4 \mathrm{v}(\mu \mathrm{L}),(\mathrm{R}=0.999)$. Aiming to confirm the linear relationship, experiments were carried out at several days. The assays were done settling different values of potential difference and no significant difference was observed.

Every day prior to begin the first titration run, the calibration stage was accomplished in order to find the parameters related to the linear relationship, which were incorporated in the control software to permit that the volume of titrant solution was calculated when titration run was ended. Intending to prove the ability of the device to deliver a preset solution volume, a set of experiments was performed using distilled water and results are showed in Table 3. Processing these data, a linear relationship presenting a slope of 0.999 and an intercept tending to 0.0 was achieved. These results indicated that the system was able to determine the solution volume processing the potential difference related to liquid column height. Furthermore, the precision of the delivered volumes was better than $1.0 \%(n=10)$ which was confirmed repeating the experiments maintaining the preset values.

\subsection{Automatic titration}

Aiming to demonstrate the usefulness of the proposed volume meter device, photometric titration of hydrochloric acid with sodium hydroxide solution was performed yielding the results showed in Table 4. The volumes of the $\mathrm{HCl}$ solution aliquots were varied from 43 up to $115 \mu \mathrm{L}$. As we can see the concentration of the $\mathrm{HCl}$ solution found is closed to expected values.

In the assays labeled as 5 and 6 the volumes of the $\mathrm{HCl}$ solution aliquots used were 100 and $115 \mu \mathrm{L}$, respectively, thus the solution container (TC, Figure 1) was filled twice. Analyzing the results, we can see, that in both cases accuracy and precision were similar to the other ones showed in Table 4.

\section{CONCLUSIONS}

The performance of the proposed volume meter shows that it can be used to deliver small volume with good precision 
independent of the flow rate and the time interval. The instrumental arrangement is very simple and easy to be replicated in laboratory with a few little electronic facilities.

The volume meter was successfully applied in the determination of the titrant solution volume in photometric titration procedure of hydrochloric acid with sodium hydroxide solution. Albeit, the operational work range was between 5 and $105 \mu \mathrm{L}$, the appropriated combination of software and hardware were able to refill the titrant solution container while the titration run was in course.

The volume meter device presented a very good longterm stability, which was ascertained by working several days and no significant variation concerning to linear response range, precision, and accuracy was observed.

\section{ACKNOWLEDGMENTS}

Authors gratefully acknowledge the Fundação de Amparo à Pesquisa do Estado de São Paulo (FAPESP) and the Conselho Nacional de Desenvolvimento Científico e Tecnológico do Brasil $(\mathrm{CNPq})$ for the financial support.

\section{REFERENCES}

[1] J. F. van Staden, M. G. Mashamba, and R. I. Stefan, "Determination of the total acidity in soft drinks using potentiometric sequential injection titration," Talanta, vol. 58, no. 6, pp. 1109-1114, 2002.

[2] J. Marcos, A. Ríos, and M. Valcárcel, "Automatic titrations in unsegmented flow systems based on variable flow-rate patterns_part 1: principles and applications to acid-base titrations," Analytica Chimica Acta, vol. 261, no. 1-2, pp. 489 494, 1992.

[3] I. L. García, P. Vinas, N. Campillo, and M. H. Córdoba, "Linear flow gradients for automatic titrations," Analytica Chimica Acta, vol. 308, no. 1-3, pp. 67-76, 1995.

[4] P. B. Martelli, B. F. Reis, M. Korn, and J. L. F. C. Lima, "Automatic potentiometric titration in monosegmented flow system exploiting binary search," Analytica Chimica Acta, vol. 387, no. 2, pp. 165-173, 1999.

[5] A. P. S. Paim, C. M. N. V. Almeida, B. F. Reis, R. A. S. Lapa, E. A. G. Zagatto, and J. L. F. C. Lima, "Automatic potentiometric flow titration procedure for ascorbic acid determination in pharmaceutical formulations," Journal of Pharmaceutical and Biomedical Analysis, vol. 28, no. 6, pp. 1221-1225, 2002.

[6] R. S. Honorato, E. A. G. Zagatto, R. A. C. Lima, and M. C. U. Araújo, "Prior assay as an approach to flow titrations. Spectrophotometric determination of iron in alloys and ores," Analytica Chimica Acta, vol. 416, no. 2, pp. 231-237, 2000.

[7] J. Marcos, A. Ríos, and M. Valcárcel, "Automatic titrations in unsegmented flow systems based on variable flow-rate patterns-part 2: complexometric and redox titrations," Analytica Chimica Acta, vol. 261, no. 1-2, pp. 495-503, 1992.

[8] H. du Plessis and J. F. van Staden, "Determination of sulphuric acid in process effluent streams using sequential injection titration," Talanta, vol. 52, no. 1, pp. 83-90, 2000.

[9] M. Korn, L. F. B. P. Gouveia, E. de Oliveira, and B. F. Reis, "Binary search in flow titration employing photometic endpoint detection," Analytica Chimica Acta, vol. 313, no. 3, pp. 177-184, 1995.

[10] A. J. C. Garcia and B. F. Reis, "Instrumentation and automated photometric titration procedure for total acidity determina- tion in red wine employing a multicommuted flow system," Journal of Automated Methods and Management in Chemistry, vol. 2006, Article ID 83247, 8 pages, 2006.

[11] F. R. P. Rocha, B. F. Reis, E. A. G. Zagatto, J. L. F. C. Lima, R. A. S. Lapa, and J. L. M. Santos, "Multicommutation in flow analysis: concepts, applications and trends," Analytica Chimica Acta, vol. 468, no. 1, pp. 119-131, 2002.

[12] A. F. Lavorante, M. A. Feres, and B. F. Reis, "Multicommutation in flow analysis: a versatile tool for the development of the automatic analytical procedure focused on the reduction of reagent consumption," Spectroscopy Letters, vol. 39, no. 6, pp. 631-650, 2006.

[13] E. Ródenas-Torralba, F. R. P. Rocha, B. F. Reis, Á. MoralesRubio, and M. de La Guardia, "Evaluation of a multicommuted flow system for photometric environmental measurements," Journal of Automated Methods and Management in Chemistry, vol. 2006, Article ID 20384, 9 pages, 2006.

[14] F. R. P. Rocha and B. F. Reis, "A low-cost device for automatic photometric titrations," Journal of Chemical Education, vol. 77, no. 2, pp. 258-261, 2000. 


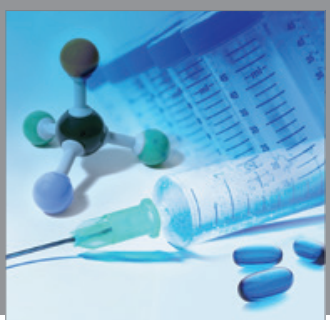

International Journal of

Medicinal Chemistry

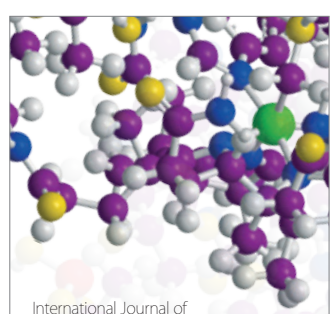

Carbohydrate Chemistry

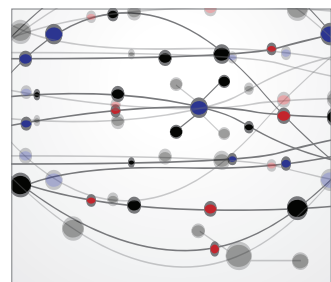

The Scientific World Journal
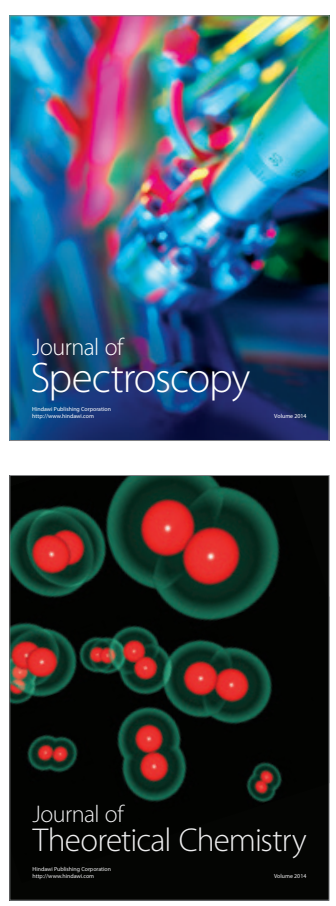
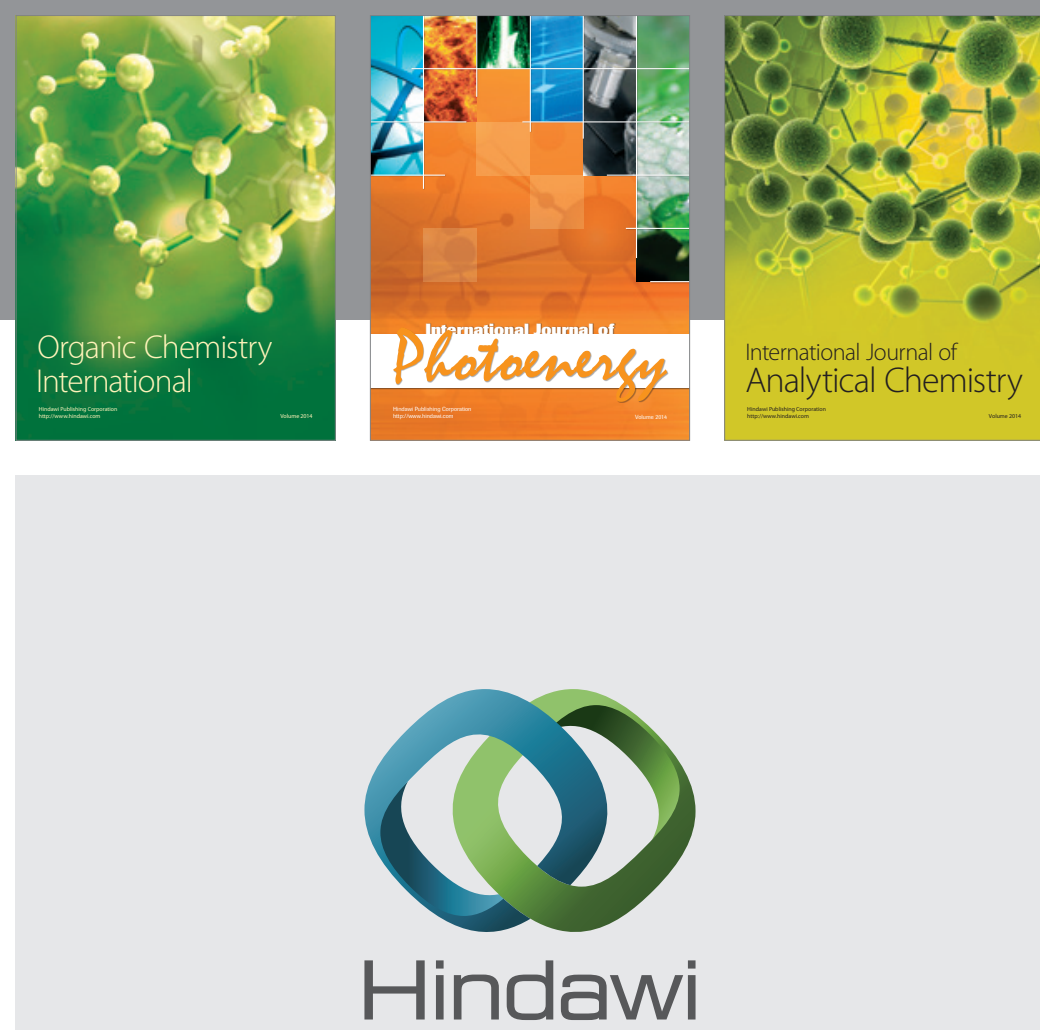

Submit your manuscripts at

http://www.hindawi.com
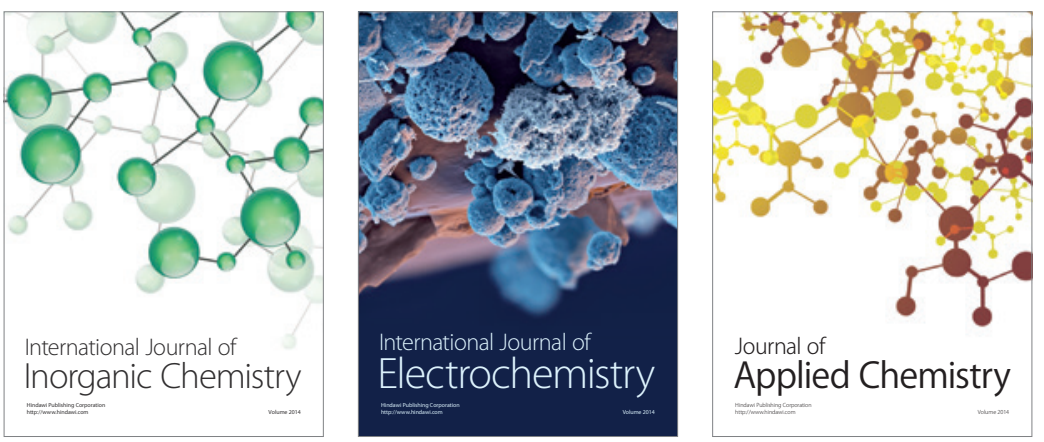

Journal of

Applied Chemistry
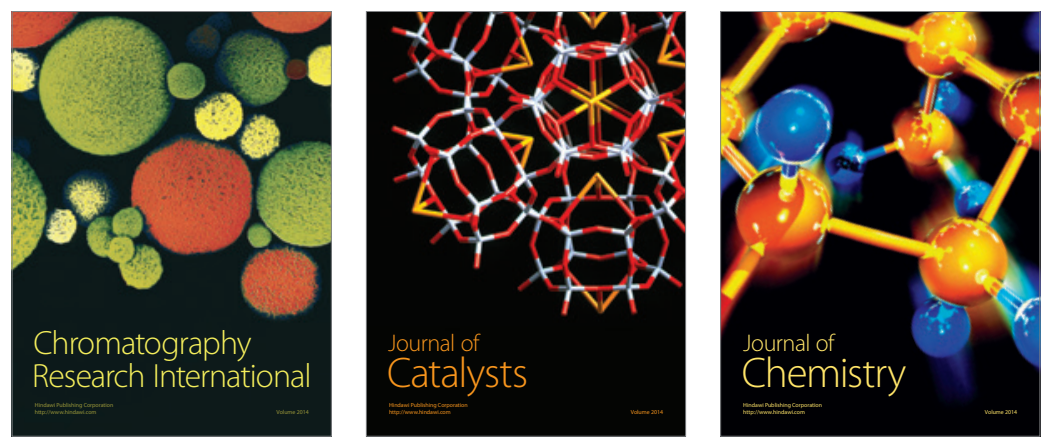
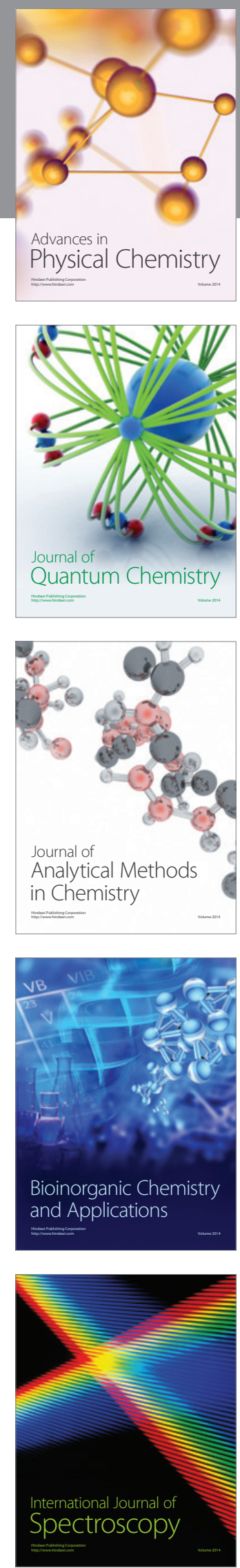